\title{
Combined Use of Biologically Active Hemostatic and Granulated Sorbent in Endoscopic Cytoprotective Hemostasis in Patients with Bleeding Gastroduodenal Ulcers
}

\author{
Evgeniy F. Cherednikov, $\mathrm{PhD}, \mathrm{ScD}^{1}$; Sergey V. Barannikov, $\mathrm{PhD}^{1}$; Alexandr I. Zhdanov, \\ $\mathrm{PhD}, \mathrm{ScD}^{1}$; Ivan P. Moshurov. $\mathrm{PhD}, \mathrm{ScD}^{1}$; Galina V. Polubkova, $\mathrm{PhD}^{1}$; Yuri V. Maleev, \\ $\mathrm{PhD}, \mathrm{ScD}^{2}$; Evgeniy S. Ovsyannikov, $\mathrm{PhD}^{1^{*}}$; Darya S. Myachina, $\mathrm{PGS}^{1}$ \\ ${ }^{I}$ Voronezh State Medical University named after N. N. Burdenko \\ ${ }^{2}$ Voronezh Basic Medical College \\ Voronezh, the Russian Federation
}

\begin{abstract}
Background: The treatment of ulcerative gastroduodenal bleeding remains one of the most acute problems in emergency surgery. The aim of our research was to improve the results of treatment of patients with bleeding gastroduodenal ulcers through the use of endoscopic pneumatic applications of platelet-rich auto-plasma and the cytoprotective sorbent Aseptisorb-A.

Methods and Results: The study included 112 patients with bleeding gastroduodenal ulcers. All patients were divided, by random sampling, into two equivalent groups: the main group $(n=57)$ and the comparison group $(n=55)$. In the treatment of patients in the main group, an individual approach was applied that used Aseptisorb-A and biologically active hemostatic agent plateletrich auto-plasma in the complex endoscopic treatment of gastroduodenal ulcers complicated by bleeding. In the comparison group, traditional methods of endoscopic hemostasis were used without platelet-rich auto-plasma and granular sorbents. After that, complex treatment of patients in the main group and comparison group did not differ. The relapse rate and operational activity was $3.5 \%$ in the main group and $10.9 \%$ in the comparison group $(P=0.04)$; mortality rate was $1.75 \%$ in the main group and $5.45 \%$ in the comparison group; the duration of inpatient treatment in the main group and the comparison group was noted within $6.0(5.0 ; 7.0)$ and 9.0(8.0;10.0) days, respectively $(P<0.01)$.

Conclusion: The developed method for treatment of ulcerative gastroduodenal bleeding with the combined use the cytoprotective sorbent Aseptisorb-A and a biologically active hemostatic agent platelet-rich auto-plasma, for the reliability of endoscopic hemostasis, reduces the number of emergency operations by 2.6 times, mainly due to a decrease in the number of rebleedings and, as a consequence, leads to a decrease in postoperative mortality by 3.1 times. (International Journal of Biomedicine. 2020;10(2):129-132.)
\end{abstract}

Key Words: bleeding gastroduodenal ulcers $\bullet$ endoscopic hemostasis $\bullet$ cytoprotective sorbents $\bullet$ hemostatic agents $\bullet$ platelet-rich auto-plasma

\section{Introduction}

The treatment of ulcerative gastroduodenal bleeding remains one of the most acute problems in emergency surgery. The number of patients with gastroduodenal bleeding does not decrease, and even tends to increase. ${ }^{(1-4)}$ The leading treatment of patients with gastroduodenal bleeding is therapeutic

*Corresponding author: Evgeniy S. Ovsyannikov, PhD. Department of faculty therapy, Voronezh State Medical University named after N.N. Burdenko.Voronezh, Russia. E-mail: ovses@yandex.ru endoscopy. However, despite the variety of methods for endoscopic hemostasis, the number of relapses of bleeding, even when using modern combined methods of endoscopic hemostasis ranges from $10 \%$ to $46 \%$. Mortality in patients with ulcerative gastroduodenal bleeding reaches $5 \%-15 \%$, and with the recurrence of bleeding, it increases to $30 \%-40 \%$. These circumstances show an urgent need to develop new, highly effective methods for gastrointestinal bleeding treatment. (5-9) $^{(5)}$

Many authors note that it is important not only to stop gastroduodenal bleeding, but also to create conditions for the rapid healing of a peptic ulcer, which is a possible source 
of complications. ${ }^{(10-12)}$ To accomplish this important task, biologically active drainage sorbents that have pronounced hydrophilicity and adhesiveness, endowed with cytoprotective, hemostatic, antibacterial and other properties, have been successfully used for more than 27 years. However, a number of authors note that these sorbents do not have such a pronounced hemostatic activity and their use as monotherapy in patients with bleeding gastroduodenal ulcers may be accompanied by a relapse of hemorrhage..$^{(13-15)}$

The use of biologically active cytoprotective sorbents in combination with hemostatic drugs seems to be promising. One of the highly effective hemostatic agents is plateletrich plasma. As a hemostatic and reparative drug, it has been successfully used in various fields of clinical medicine: for example, cardiovascular surgery, thoracic surgery, traumatology, and purulent surgery. However, platelet-rich plasma has not been previously used for endoscopic treatment of gastrointestinal bleeding of ulcerative etiology.

The aim of our research was to improve the results of treatment of patients with bleeding gastroduodenal ulcers through the use of endoscopic pneumatic applications of platelet-rich auto-plasma and the cytoprotective sorbent Aseptisorb-A.

\section{Materials and Methods}

A clinical study was conducted in the Voronezh City Specialized Center for the treatment of patients with gastrointestinal bleeding. The study included 112 patients with bleeding gastroduodenal ulcers.

Among all patients with gastroduodenal bleeding, there were $79(71 \%)$ men and 33(29\%) women. The average age of patients was $57.5(44.5 ; 67.5)$ years. Upon admission, all patients underwent emergency esophagogastroduodenoscopy (EFGDS). Depending on the source of bleeding, patients were divided as follows: symptomatic gastroduodenal ulcers -78(69.6\%); peptic ulcer and duodenal ulcer - 34(30.4\%). According to the endoscopic classification, ${ }^{(16)}$ patients were divided as follows: continued bleeding (Forrest Ia-Ib) - 20(17.9\%); threat of rebleeding (Forrest IIa-IIb) - 64(57.1\%); signs of completed bleeding (Forrest IIc) - 28(25.0\%). The severity of blood loss was evaluated according to the classification of A.I. Gorbashko (1982): mild severity was observed in $41(36.6 \%)$ patients, moderate in $61(54.5 \%)$ and severe in $10(8.9 \%)$.

All patients were divided, by random sampling, into two equivalent groups: the main group $(n=57)$ and the comparison group $(n=55)$. Patients were comparable in etiology of ulcerative bleeding, age, gender, size of bleeding defect, degree of severity of bleeding, nature of bleeding according to endoscopic classification, and duration of observations.

In the treatment of patients in the main group, an individual approach was applied that used Aseptisorb-A and biologically active hemostatic agent platelet-rich auto-plasma in the complex endoscopic treatment of gastroduodenal ulcers complicated by bleeding (Patent RF № 2632771). In particular, in patients with ongoing hemorrhage (Forrest Ia-Ib), active bleeding was stopped first by injection with aminocaproic acid, then with vasoconstrictor drugs, followed by argon- plasma coagulation; and then Aseptisorb-A was pneumatically insufflated onto the defect area followed by application of platelet-rich auto-plasma. In patients with the threat of rebleeding (Forrest IIa-IIb), the argon-plasma coagulation of the thrombosed vessel (Forrest IIa) was first performed, and in Forrest IIb, the clot was first removed from the ulcer defect by washing it, then the argon-plasma coagulation of the bleeding source was also performed. After that, with the help of an insufflator, Aseptisorb-A powder was applied to the area of these ulcerative defects, followed by the application of the patient's platelet-rich auto-plasma. With the Forrest IIc type of bleeding, with the aim of preventing the recurrence of hemorrhage, Aseptisorb-A and platelet-rich auto-plasma were applied to the defect according to the developed technique.

In the comparison group, traditional methods of endoscopic hemostasis (injection method, argon plasma coagulation, etc.) were used without platelet-rich auto-plasma and granular sorbents. After that, complex treatment of patients in the main group and comparison group did not differ.

The main criteria in assessing the results of treatment were both clinical and endoscopic indicators: the timing of the final hemostasis, the frequency of rebleeding, dynamic monitoring of the size of ulcerative defects, the quality of healing of ulcers, the presence of emergency operations, and mortality rates.

Statistical analysis was performed using Microsoft Excel software package. For descriptive analysis, results are presented as mean \pm standard deviation (SD), median (Me), interquartile range (IQR), minimum and maximum values. Wilcoxon rank sum test was used to test for difference in medians. Group comparisons with respect to categorical variables were performed using Fisher's exact test. A probability value of $P<0.05$ was considered statistically significant.

\section{Results and Discussion}

When evaluating the results of treatment of patients in the main group with ongoing bleeding (Forrest Ia-Ib), it was noted that primary endoscopic hemostasis was achieved in all 10 patients. Clinical observations showed that in patients who received endoscopic treatment according to the developed technique, after pneumo-insufflation on a bleeding ulcer defect of Aseptisorb-A, followed by the application of plateletrich auto-plasma, the granular sorbent swelled, turning into a soft elastic hydrogel that was tightly fixed in the area of the bleeding source due to its properties, protecting it from the effects of aggressive factors of the gastric and duodenal contents. With repeated esophagogastroduodenoscopy, it was found that the drug hydrogel was retained on the ulcer defect for up to 4 days. In this case, rebleeding and emergency operations in this group of patients was not detected.

Endoscopic primary hemostasis in the comparison group was also achieved in all 10 patients; however, in 1 patient, a ulcer rebleeding clinic appeared on Day 3 of treatment. This patient was urgently operated on "at the height of bleeding." The postoperative period was complicated by pneumonia and on Day 6 after the operation, the patient died. 
Regarding patients with unstably stopped bleeding (Forrest IIa-IIb), 2 of 34 patients $(5.9 \%)$ in the main group experienced a relapse of bleeding. These patients were operated on, on an emergency basis. The cause of rebleeding was penetrating ulcers of the duodenal bulb and stomach. One patient was discharged home in satisfactory condition on Day 12 of treatment, and another patient died in the postoperative period against the background of severe concomitant pathology.

Among 30 patients of the comparison group with the Forrest IIa-IIb bleeding, recurrence of ulcerative bleeding was observed in 4(13.3\%) cases. Due to the failure of repeated endoscopic hemostasis, three patients were operated on "at the height of bleeding," and two of them died in the presence of severe concomitant pathology and increasing multiple organ failure in the postoperative period.

In 13 patients of the main group with Forrest IIc, there was no recurrence of hemorrhage, and there were no operations or fatal outcomes. In the comparison group, among 15 patients with bleeding, 1 patient on Day 2 of inpatient treatment revealed a relapse of bleeding, which was stopped endoscopically. However, due to the high risk of rebleeding, the patient was operated on urgently and was discharged after surgery for outpatient treatment.

In patients of the two compared groups, studies were conducted on the dynamics of indicators of a general blood test (hemoglobin, red blood cells, white blood cells) at the stages of the study. The level of hemoglobin upon admission in patients in the main group and comparison group was comparable: $109.0(95.0 ; 120.0) \mathrm{g} / \mathrm{L}$ and $110.0(100.0 ; 122.0)$ $\mathrm{g} / \mathrm{L}$, respectively $(P>0,05)$ In patients of both groups, the hemoglobin and erythrocyte counts decreased for 2-3 days, which is associated with developing hemodilution; however, in the comparison group, a decrease in the level of hemoglobin occurred more significantly $[94(82.0 ; 105.0) \mathrm{g} / \mathrm{L}]$ than in the main group $[100.0(90.0 ; 106.0) \mathrm{g} / \mathrm{L}]$, which is explained by a large number of rebleedings. Starting from Days 4-5, there was an increase in the hemoglobin level up to $109.0(98.0 ; 116.0) \mathrm{g} / \mathrm{L}$ in the main group and $95.0(85.0 ; 108.0) \mathrm{g} / \mathrm{L}$ in the comparison group. When patients were discharged from the hospital, the hemoglobin level was $117.0(104.0 ; 125.0) \mathrm{g} / \mathrm{L}$ in the main group and $98.0(86.0 ; 112.0) \mathrm{g} / \mathrm{L}$ in the comparison group $(P<0.001)$. A similar dynamics was observed when studying the levels of red blood cells and hematocrit in the compared groups.

In the final assessment of the results of the clinical study, it was found that the final endoscopic hemostasis was achieved in 55(96.5\%) patients of the main group and in 49(89.1\%) patients of the comparison group $(P>0.05)$. The relapse rate and operational activity was $3.5 \%$ in the main group and $10.9 \%$ in the comparison group; operational activity was $3.5 \%$ in the main group and $9.1 \%$ in the comparison group. Moreover, mortality rate was $1.75 \%$ in the main group and $5.45 \%$ in the comparison group; the duration of inpatient treatment in the main group and the comparison group was noted within 6.0(5.0;7.0) and 9.0(8.0;10.0) days, respectively $(P<0.01)$.

In conclusion, the developed method for treatment of ulcerative gastroduodenal bleeding with the combined use the cytoprotective sorbent Aseptisorb-A and a biologically active hemostatic agent platelet-rich auto-plasma, for the reliability of endoscopic hemostasis, reduces the number of emergency operations by 2.6 times, mainly due to a decrease in the number of rebleedings and, as a consequence, leads to a decrease in postoperative mortality by 3.1 times.

\section{Competing Interests}

The authors declare that they have no competing interests.

\section{Sources of Funding}

This work was partially supported by the Council on Grants of the President of the Russian Federation for State Support of Young Scientists and Leading Scientific Schools (Grant MK-1069.2020.7).

\section{References}

1. Budnevsky AV, Cherednikov EF, Popov AV, Ovsyannikov ES, Kravchenko AY, Kuranosov AY, Fursov KO. A complex, multidisciplinary approach to prevention of gastro-duodenal bleeding in therapeutic patients of a general hospital. International Journal of Biomedicine. 2017;7(3):204-207.

2. Shapkin YG, Potahin SN. [The dynamics of main indicators for the treatment of ulcerative gastroduodenal bleeding - the analysis of several years studies]. Saratov Journal of Scientific Research. 2014;10(3):456-460. [Article in Russian].

3. Cherednikov EF, Barannikov SV, Romantsov MN, Popov AV. New aspects of preventive endoscopic hemostasis in the treatment of peptic ulcer bleeding in the experimental condition. The EPMA Journal. 2017;8(S1):45.

4. Adianov VV, Cherednikov EF. [Optimizing treatment of gastroduodenal bleeding in patients with high surgical risk]. System Analysis and Management in Biomedical Systems. 2014; 13(4): 841-846. [Article in Russian].

5. Cherednikov EF., Budnevsky AV, Popov AV, Fursov $\mathrm{KO}$. A new opinion on gastroduodenal bleeding preventon in patients with somatic patology. The EPMA Journal. 2017; 8(S1):46.

6. Budnevsky AV, Popov Art V, Cherednikov EF. [Erosiveulcerative lesions of the stomach and duodenum in therapeutic patients: prevention of bleeding]. Nauchno-medicinskij vestnik Central'nogo CHernozem'ya. 2016;65:64-71. [Article in Russian].

7. Deryaeva OG, Cherednikov EF. [Multimodality therapy of erosiveulcer gastroduodenal bleeding by patients in a multidisciplinary hospital]. System Analysis and Management in Biomedical Systems. 2014; 13(3):725-730. [Article in Russian].

8. Cherednikov EF, Deryaeva OG, Cherednikov EE, Adianov VV, Bondarenko AA, Yakushev FK. [The effectiveness of the modern approach to the treatment of patients with gastroduodenal bleeding in a multidisciplinary hospital]. Nauchno-medicinskij vestnik Central'nogo CHernozem'ya. 2016;65:20-25. [Article in Russian].

9. Romantsov MN, Cherednikov EF, Glukhov AA, Fursov KO. [New technologies of endoscopic hemostasis in the 
treatment protocol of patients with gastroduodenal ulcer bleeding]. Journal of Experimental and Clinical Surgery. 2018;11(1):16-23. [Article in Russian].

10. Cherednikov EF, Barannikov SV, Maleev YuV, Fursov KO, Litovkina TE, Zakurdaev EI, Ovsyannikov ES. Experimental justification of using Aseptisorb-A and platelet-rich plasma in endoscopic treatment of mold bleeding stomach defects. International journal of biomedicine. 2017;7(4):298-301. 11. Cherednikov EF, Barannikov SV, Fursov KO, Polubkova GV, Danilenko VI, Stepanov DS. [Healing of bleeding experimental defects of the stomach with topical anilovin and platelet-rich plasma]. Journal of Volgograd State Medical University. 2017; 2(62): 130-133. [Article in Russian]. 12. Romantsov MN, Cherednikov E F, Danilenko VI, Stepanov DS, Fursov K O, Deryaeva AG. [Morphological Characteristics of Processes of Simulated Bleeding Gastric Defects Reparation in Treatment with Gelplastan and Diovin]. Journal of Anatomy and Histopathology. 2017;6(1):81-86. [Article in Russian].
13. Cherednikov EF, Kashurnikova MA, Romantsov MN, Barannikov SV, Bolkhovitinov A E, Gaponenkov DG, Lyubimov PYu. Experimental study of new means of local hemostasis in the treatment of gastric bleeding. Nauchnomedicinskij vestnik Central'nogo CHernozem'ya. 2016; 65: 27-33. [Article in Russian].

14. Cherednikov EF, Barannikov SV, Maleev YuV, Fursov KO, Litovkina T E, Zakurdaev EI. [Experimental justification of the use of biologically active draining sorbent and plasma enriched by thrombocytes in treatment of bleeding defects of the stomach]. Journal of New Medical Technologies. 2017;24(2):114-118. [Article in Russian].

15. Cherednikov EF, Batkaev AR, Baev VE. The Reparative regeneration of erosive-ulcerative lesions of the stomach and duodenum in the local treatment of hydrophilic granular sorbents. System Analysis and Management in Biomedical Systems. 2005;4(2):224-225. [Article in Russian].

16. Forrest JA, Finlayson ND, Shearman DJ. Endoscopy in gastrointestinal bleeding. Lancet. 1974;2(7877):394-7. 